\title{
Erratum zu: ,Fill, Anna (2019): The Political Economy of De-liberalization. A Comparative Study on Austria, Germany and Switzerland“6
}

\author{
Reimut Zohlnhöfer
}

Online publiziert: 11 . November 2021

(C) Der/die Autor(en) 2021

\section{Erratum zu:}

\section{Polit Vierteljahresschr 2020}

https://doi.org/10.1007/s11615-020-00217-7

Der Artikel „Fill, Anna (2019): The Political Economy of De-liberalization. A Comparative Study on Austria, Germany and Switzerland" von Reimut Zohlnhöfer wurde ursprünglich am 31. Januar 2020 ohne „Open Access“ online auf der Internetplattform des Verlags publiziert. Der Autor hat sich jedoch nachträglich für eine „Open Access"-Veröffentlichung entschieden. Das Urheberrecht des Artikels wurde deshalb am 16. September 2021 in () Der/die Autor(en) 2020 geändert.

Funding Open Access funding enabled and organized by Projekt DEAL

Open Access Dieser Artikel wird unter der Creative Commons Namensnennung 4.0 International Lizenz veröffentlicht, welche die Nutzung, Vervielfältigung, Bearbeitung, Verbreitung und Wiedergabe in jeglichem Medium und Format erlaubt, sofern Sie den/die ursprünglichen Autor(en) und die Quelle ordnungsgemäß nennen, einen Link zur Creative Commons Lizenz beifügen und angeben, ob Änderungen vorgenommen wurden.

Die in diesem Artikel enthaltenen Bilder und sonstiges Drittmaterial unterliegen ebenfalls der genannten Creative Commons Lizenz, sofern sich aus der Abbildungslegende nichts anderes ergibt. Sofern das betreffende Material nicht unter der genannten Creative Commons Lizenz steht und die betreffende Handlung nicht nach gesetzlichen Vorschriften erlaubt ist, ist für die oben aufgeführten Weiterverwendungen des Materials die Einwilligung des jeweiligen Rechteinhabers einzuholen.

Weitere Details zur Lizenz entnehmen Sie bitte der Lizenzinformation auf http://creativecommons.org/ licenses/by/4.0/deed.de.

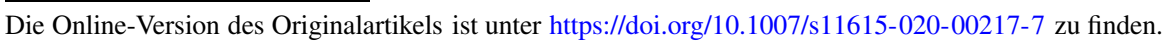

Reimut Zohlnhöfer $(\bowtie)$

Heidelberg, Deutschland

E-Mail: reimut.zohlnhoefer@ipw.uni-heidelberg.de 